\title{
The Global Impacts of Extreme Sea-Level Rise: A Comprehensive Economic Assessment
}

\author{
Jonathan Pycroft $\cdot$ Jan Abrell · Juan-Carlos Ciscar
}

Accepted: 16 December 2014 / Published online: 11 January 2015

(C) The Author(s) 2015. This article is published with open access at Springerlink.com

\begin{abstract}
This paper investigates the world-wide economic cost of rapid sea-level rise of the kind that could be caused by accelerated ice flow from the West Antarctic and/or the Greenland ice sheets. Such an event would have direct impacts on economic activities located near the coastline and indirect impacts further inland. Using data from the DIVA model on sea floods, river floods, land loss, salinisation and forced migration, we analyse the effects of these damages in a computable general equilibrium model for 25 world regions. We consider three sea-level rise scenarios that correspond to $0.47,1.12$ and $1.75 \mathrm{~m}$ by the $2080 \mathrm{~s}$. By incorporating a wider range of damage categories, implemented in an economy-wide framework and including very rapid sea-level rise, the study offers a new contribution to climate change impact studies. We find that the loss of GDP worldwide is $0.5 \%$ in the highest sea-level rise scenario, with a loss of welfare (equivalent variation) of almost $2 \%$ world-wide. Within these aggregates, there are large regional disparities, with the Central Europe North region and parts of South-East Asia and South Asia being especially prone to high costs (welfare losses in the range of 4-12\%). The analysis assumes that there is not public adaptation, which would substantially lower the costs. In this way, the analysis demonstrates what is at risk, and could be used to justify adaptation expenses.
\end{abstract}

Keywords Climate change $\cdot$ Sea-level rise $\cdot$ Computable general equilibrium (CGE) models $\cdot$ Impact assessment

J. Pycroft $(\bowtie) \cdot$ J. Abrell · J.-C. Ciscar

Institute for Prospective Technological Studies (IPTS),

European Commission, Calle Inca Garcilaso, 3, 41092 Seville, Spain

e-mail: Jonathan.Pycroft@ec.europa.eu; jonathan.pycroft@oxon.org

J. Abrell

Centre for Energy Policy and Economics,

ETH Zurich, Rämistrasse 101, 8092 Zurich, Switzerland 


\section{Introduction}

Coastal regions provide important services and functions for the economy. Many major settlements have developed in low-lying coastal zones, often driven by the importance of water transport. The prospect of a changing sea level has significant direct implications for most countries and many major cities around the world (Nicholls et al. 2007), and is often cited as one of the reasons for concern about climate change (Smith et al. 2009).

Moreover, the coastal impact category is one of the most important ones in comparative terms. For instance, Ciscar et al. (2014) consider eight different impact categories (including e.g. agriculture, energy, tourism and forest fires) in an assessment of climate impacts in Europe, without public adaptation. They found coastal damages to be the most important impact category among the market impacts.

An indication of the scale of the people and economic activity potentially impacted by sea-level rise (SLR) is suggested in Dasgupta et al. (2009) who use satellite data of land usage to calculate the percentage of GDP and population that would be impacted by multi-metre SLR in 84 developing countries. In these countries it is estimated that roughly $2 \%$ of GDP and population are within the inundation zone for a 2 -m SLR.

Other studies identify significant potential impacts at regional and local scales. For instance, Heberger et al. (2011) analyse key categories of infrastructure located in coastal zones in California. They note that if sea-level rose by $1.4 \mathrm{~m}, 56$ schools, 13 healthcare facilities and 330 sites containing hazardous materials would be at risk from a 100-year flood event. They also identify 28 wastewater treatment plants and 30 coastal power plants that would be at risk under such circumstances. Other studies identifying micro-scale impacts include Delta Committee (2008) and Koningsveld et al. (2008), for the Netherlands, Breil et al. (2005), for the city of Venice, Saizar (1997), for Montevideo, Morisugi et al. (1995), for Ise Bay in Japan and Smith and Lazo (2001) who summarise country-level and sub-country-level studies from all continents. Losada et al. (2013), which investigates the impact of rising sea levels around the Latin American and Caribbean coast, emphasises the importance of considering changes in storm surges and extreme coastal events. ${ }^{1}$

There is considerable uncertainty over the amount of SLR that should be expected as a result of climate change. Estimates for this century range from a few decimetres to multi-metre rises, depending crucially on the response of large ice sheets to a warming climate. Nicholls et al. (2008) investigate the global impact were extreme SLR to occur. Specifically, the paper considers the collapse of the West Antarctic Ice Sheet, which is assumed to cause an additional $5 \mathrm{~m}$ of SLR. The earliest year considered for complete collapse is 2130 (representing very fast collapse), and later dates are also considered. This work utilises the DIVA model, and considers the impacts from land loss, wetland loss, protection costs and forced migration. The model allows for coastal land to either be defended (if the benefits of doing so outweigh the costs) or abandoned (if not). Different types of impacts are estimated, including, for the most extreme scenario, the cost of coastal protection, which would rise to around $\$ 30$ billion per year by the end of the century, and the number of people forced to migrate, which would peak at around 350,000 people per year in the 2040s.

Computable general equilibrium (CGE) models can be used to assess the overall economic implications of SLR, on top of the direct economic impacts. An early CGE study looking into the economy-wide impacts of SLR is Darwin and Tol (2001). The paper utilises the Future Agricultural Resources Model (FARM), which contains an eight-region CGE model,

1 The DIVA model used in this study does take account of storm surges and extreme weather events (see Sect. 3). 
to investigate the economic implications of a $0.5 \mathrm{~m}$ SLR. The economic loss is modelled as a loss of production capital. The article demonstrates clearly the importance of changes in consumer prices caused by SLR impacts, as well as the importance of international trade, both of which are captured within a CGE framework, but not with direct cost estimates.

Deke et al. (2001) also use a global CGE model and assume that all threatened coastal zones are protected, so that the shock is the cost of protection, which is subtracted from investment elsewhere in the economy. The welfare losses across the eleven world regions considered range from $-0.006 \%$ in Western Europe to $-0.309 \%$ in both India and Pacific Asia. The main reason for the relatively low welfare losses is that the SLR projections are at the low end of the IPCC range (13-14 $\mathrm{cm}$ by 2100).

Bosello et al. (2007) employ the GTAP-EF CGE model, ${ }^{2}$ which divides the world into eight regions, assuming $25 \mathrm{~cm}$ SLR by 2050. They emphasise the need for general equilibrium effects to be considered, arguing that estimates using direct costs alone can be significantly biased, typically underestimating the costs. Bosello et al. (2012) use the same model to make a more detailed assessment for EU countries using direct costs from the DIVA model as an input. It is interesting to note that only land losses and adaptation costs are used when entering shocks into the CGE model, with land losses being used to shock productive agriculture. The other components of SLR damages, mainly sea floods and migration costs are not integrated. ${ }^{3}$ Indeed, the authors note that this approach "neglects potential effects on infrastructure, physical capital or on labour productivity caused for instance by forced displacement" (p. 74).

SLR could also influence economic growth, which is addressed in Hallegatte (2012), who inter alia considers a reduction in usable capital. Though the impact of temporary flooding on growth is found to be more ambiguous (whether damage from a natural disaster leads to a lower or higher growth path appears to be dependent on the region and the disaster in question), some of the damage would result in a permanent capital loss. This would most likely reduce long-term growth rates, and supports the notion that at least some of the economic loss can be modelled by a reduction in capital stock.

The main purpose of this article is to explore in detail the economic implications of extreme SLR scenarios, without public adaptation, under a CGE modelling setup. In particular, our paper explores two aspects not considered so far by the literature. First, we analyse the general equilibrium effects of SLR impacts for very high SLR scenarios. Three specific SLR scenarios are modelled with the DIVA model. The first one concerns a moderate SLR profile and the other two much higher SLR profiles (of 1.4 and $2 \mathrm{~m}$ by 2100 ), associated with significant ice sheet loss.

Second, this study integrates a wider range of SLR damage categories into a CGE model, deriving therefore more comprehensive estimates of economic impacts. This is in contrast to studies that have focused only on land losses, which represent a small share of the total economic damages due to SLR. In this paper we explicitly model the other key impacts, mainly the economic damages associated with forced migration and sea floods.

The damage estimates used in this paper are those without public adaptation. In cases where the damages exceed the cost of adaptation - through public sector interventions such as sea dykes and beach nourishment-countries or regions would rationally be expected to take measures to protect their coastlines. Allowing for public adaptation would reduce

\footnotetext{
2 The GTAP-EF model is a development of the GTAP-E model (Burniaux and Truong 2002), itself a development of the GTAP model (Hertel 1997).

3 Though they report direct damages from sea floods, salinisation and forced migration, these are only used in the CGE section of the paper to the extent that they are determinants of the amount of adaptation expenditure that is considered worthwhile.
} 
the damage estimates (or at least not increase them since only cost effective protection is permitted), perhaps considerably in some cases (see for example, Fankhauser 1995; Bosello et al. 2012). The estimates calculated in this paper highlight the potential damage costs that could be used to justify investment in coastal protection. Moreover, thanks to the use of the CGE methodology, private level adaptation is also considered in the analysis as all the market adjustments happening via price changes are considered in the assessment (see e.g. Aaheim et al. 2012).

The paper proceeds as follows. Section 2 explains and justifies the selected SLR scenarios. The economic estimates of the SLR direct costs from the DIVA model are explained in Sect. 3. Section 4 first outlines the main features of the CAGE computable general equilibrium (CGE) model, and the implementation of the SLR shocks into the CGE model. Section 5 reports the results and Sect. 6 concludes. The "Appendix" details the mathematical model statement for the CAGE model.

\section{Selected Sea-Level Rise Scenarios}

This section reviews the literature on SLR, which has been used as a guide for the SLR scenarios chosen for this paper. The amount of SLR that can be expected for this century has two main sources of uncertainty: the extent of the temperature rise (which itself depends partly on the actions of human society; IPCC 2007), and the response of sea level to temperature, influenced in particular by the response of ice sheets. Estimates can be made based on studies of the current ice sheet structure and behaviour, as well as analysing the geological records. One particular difficulty of this is that the potential speed of temperature change (which can be considered geologically instantaneous) is unprecedented. Therefore whilst research using the geological record has provided considerable evidence, the current situation has no close analogue from the past. Whilst one expects that estimates of ice sheet response will continue to improve, precise quantification has proved challenging due to "insufficient data and a limited ability to model the underlying process" (Kriegler et al. 2009).

According to the Fourth Assessment Report from the IPCC, the range for potential SLR is between 18 and $59 \mathrm{~cm}$ by the last decade of the twenty-first century, depending on the emission scenario (Meehl et al. 2007). This fairly modest prediction came with a vital qualification: the figure excludes the possibility of "future rapid dynamical changes in ice flow". Nevertheless, the report does discuss the threat of ice-sheet melting/collapse, with the Greenland and the West Antarctic Ice Sheets (GIS and WAIS) being considered as relatively vulnerable. Together these ice sheets hold enough $\mathrm{H}_{2} \mathrm{O}$ to cause SLR of around $12 \mathrm{~m}$ (Meehl et al. 2007). ${ }^{4}$ Although the IPCC authors were well-aware of these possibilities, they felt unable to place numerical values on the probabilities due to limitations of the available research at the time.

A key question to understand the pace of SLR is how quickly the process accelerates. Hansen (2007) describes it this way: "Ice sheet disintegration, unlike ice sheet growth, is a wet process that can proceed rapidly. Multiple positive feedbacks accelerate the process once it is underway". 5 To emphasise the importance of acceleration, the paper muses that if SLR doubles every decade, then a $1 \mathrm{~cm}$ SLR from 2005 to 2015 grows to a cumulative

\footnotetext{
4 If both the Greenland Ice Sheet and the whole of the Antarctic Ice Sheet were to melt, they "hold enough ice to raise sea level by about 64 metres" (Bentley et al. 2007:101), however the bulk of the Antarctic Ice Sheet is not considered vulnerable to collapse.

5 Rapid melting has occurred in the past, such as the rapid deglaciation 14,600 years ago known as meltwater pulse 1A, which saw a 20-m rise in less than 500 years (Weaver et al. 2003). Though clearly, the ice sheets prior to this event were considerably larger than those that exist today.
} 
total of $5 \mathrm{~m}$ SLR by 2100 . Though the numbers in this example are expositional, rather than predictive, the concept is important: ice-sheet melting, and hence sea-level rise, may well be an accelerating process, rather than a linear process.

Subsequent research is suggestive of the increasing contributions to SLR from accelerating ice flow. Velicogna (2009) uses data from the Gravity Recovery and Climate Experiment (GRACE) satellite gravity mission to show that the rate of ice loss is increasing from both the GIS and WAIS. The Copenhagen Diagnosis (2009) reports that satellites show global average sea-level rise to be $80 \%$ above the IPCC's (2007) predictions ( $3.4 \mathrm{~mm} /$ year over the past 15 years). This acceleration in SLR is consistent with a doubling in contribution from melting of glaciers, ice caps and the GIS and WAIS. This scenario is broadly corroborated by Grinsted et al. (2010). These studies suggest that currently observed melting rates lead one to expect some increasing contribution to SLR from melting ice sheets.

The Rahmstorf (2007) study is based upon a 'semi-empirical' relationship between global mean surface temperature and sea level. Applying this relationship to the warming scenarios put forward by the IPCC 4AR the projected SLR is between 0.5 and $1.4 \mathrm{~m}$. The high end of this range is used for one of the scenarios in this article.

Lowe and Gregory (2010) note the likelihood that the contributions to SLR from the ice sheets is probably substantially more than what occurred in the previous century, noting that such a change would be necessary for SLR to exceed a metre in the twenty-first century. They argue that increases of as much as $2 \mathrm{~m}$ are possible, though this is qualified by noting that such a rise is "not ... inevitable or even likely". As a 2-m rise is considered a possibility, this research uses it for its highest SLR scenario.

It is worth noting that a number of studies suggest that SLR beyond two metres is ultimately possible, or even likely, with global warming, driven by partial or complete collapse or melting of the GIS and WAIS (see Kopp et al. 2009; Lenton et al. 2008; Kriegler et al. 2009). However these studies focus on long-term changes and do not specifically address the SLR during this century.

For this research, the three selected scenarios runs are named (i) A1B, (ii) Rahm and (iii) High scenario. The A1B scenario is consistent with the A1B IMAGE scenario, which assumes a warming of $2.4{ }^{\circ} \mathrm{C}$ by the $2050 \mathrm{~s}$ and $3.8^{\circ} \mathrm{C}$ by the $2090 \mathrm{~s} .{ }^{6}$ The two rapid SLR scenarios use the upper end of the ranges proposed in the two papers noted in the previous discussion. In the Rahm scenario (Rahmstorf 2007), sea level rises by $1.4 \mathrm{~m}$ by 2100 , and in the High scenario (Lowe and Gregory 2010) by $2 \mathrm{~m}$ by 2100 . Such very high SLR scenarios represent an expansion of the literature as is outlined in Sect. 1.

In many climate impact assessments the damage estimates are computed for the average of thirty years as a way to consider a representative period of time for the climatic conditions. Thus in this study the reference period is the 2080s (meaning the average over the 2071-2100 period). The corresponding average rises in global sea level (for the year 2085) relative to preindustrial levels are $0.47,1.12$ and $1.75 \mathrm{~m}$ in the A1B, Rahm and High scenarios, respectively.

\section{Data for the Direct Costs of Sea-Level Rise}

The SLR direct costs come from the DIVA model (DINAS-Coast Consortium 2006; McFadden et al. 2007; Vafeidis et al. 2008) ${ }^{7}$ and the DIVA socio-economic scenarios (Tol 2006).

\footnotetext{
6 The DIVA model uses the A1B (IMAGE) scenario in place of the traditional IPCC A1B scenario as it provides a pattern of SLR (DIVA model notes).

7 See also http://www.diva-model.net.
} 
The DIVA model assesses the biophysical and socio-economic consequences, such as coastal flooding (including river flooding), land loss, damage from salinity and forced migration. The DIVA model itself uses data for SLR provided by the UK Met Office Hadley Centre and the multi-model climate experiment from the European Commission ENSEMBLES project. The model is well established, having been widely used for peer-reviewed publications (including for earlier estimates of SLR damages for Europe such as Bosello et al. (2012) and Ciscar et al. (2012), using the GEM-E3 model, Capros et al. (2013)).

The scenarios in this paper are named after the average global sea-level rise. Yet the DIVA model considers the regional variations of SLR (indeed SLR varies by section of coastline in the model). It takes into account the effects of erosion, inundation and salinisation for each SLR profile and computes the corresponding damage estimates for land loss (erosion and inundation), forced migration (erosion and inundation), expected coastal and river flood damage (inundation) and salinisation costs (salinisation). The DIVA calculation of the damage estimates is as follows (see Tol 2006, for details). Firstly, sea-flood damage estimates are based on expected damages from flooding that are expected once per year, once per 10 years, once per 100 years and once per 1,000 years, with each category having progressively higher damages. The damage is dependent on a "maximum possible damage", the income density and the height of the flood. For river-flood damage estimates, the procedure is similar to that for sea floods. This category becomes more important for rivers with large coastal flood plains. Salinisation damage estimates are based on the potential loss of value of salinated agricultural land (salt-tolerant crops are considered unlikely to be good substitutes for currently popular crops).

The final category of damage is the number of forced migrants due to SLR. That number is defined as the coastal area permanently flooded multiplied by the population density. Given that the year-to-year variability of the number of forced migrants is very high, the average annual value for the 2071-2100 period has been allocated to the 2080s. The economic valuation of the damage due to forced migration (which can be interpreted as the willingness to pay to not migrate) is assumed to be three times GDP per capita, following Tol (2006). ${ }^{8}$

The consequent direct damage shocks are provided in Table 1. The total global damage under the A1B scenario is estimated to be $\$ 253$ billion, which can more than double, to $\$ 550$ billion, under the High scenario. Most of the damage is associated with sea floods, river floods, salinization and land loss. It should be noted that sea floods costs represent the bulk of the impacts within that category. Interestingly, when higher sea level rise scenarios are considered the share of the migration costs in the total damage rises (from $5 \%$ in the A1B scenario to $12 \%$ in the High scenario).

Regarding the regional pattern of damages, Asia experiences most of the damages, mainly in China, Rest of South-east Asia, India, Korea and Japan. In Europe damages are much higher in the Central Europe (North) region, compared to other European regions. Damages in the USA are also large, especially migration costs, and overall are similar to those of the Central Europe (North) region.

\section{Modelling Methodology for Economy-Wide Impacts}

This section reviews the main features of the CAGE model (the CGE model employed in this study) and explains how the direct cost estimates described in the previous section are integrated into the model.

\footnotetext{
8 It is assumed that people permanently migrate to a new location, with relatively high associated migration costs (the cost per migrant is assumed to be three times the per capita income, as already noted). Consequently, possible productivity losses associated to temporary migration are not considered.
} 
Table 1 Total 2080s direct damage shock from sea floods, river floods, salinisation and land loss (summed together, Floods + Salinstn + LandLoss) and migration (billion \$)

\begin{tabular}{|c|c|c|c|c|c|c|}
\hline \multirow[t]{2}{*}{ Region } & \multicolumn{3}{|c|}{ Floods + Salinstn + LandLoss } & \multicolumn{3}{|c|}{ Migration $^{\mathrm{a}}$} \\
\hline & $\begin{array}{l}\text { A1B } \\
(0.47 \mathrm{~m})\end{array}$ & $\begin{array}{l}\text { RAHM } \\
(1.12 \mathrm{~m})\end{array}$ & $\begin{array}{l}\text { High } \\
(1.75 \mathrm{~m})\end{array}$ & $\begin{array}{l}\text { A1B } \\
(0.47 \mathrm{~m})\end{array}$ & $\begin{array}{l}\text { RAHM } \\
(1.12 \mathrm{~m})\end{array}$ & $\begin{array}{l}\text { High } \\
(1.75 \mathrm{~m})\end{array}$ \\
\hline China & 64.2 & 95.8 & 118.4 & 5.7 & 4.5 & 4.5 \\
\hline Japan & 4.8 & 11.3 & 15.2 & 0.0 & 6.9 & 4.6 \\
\hline Korea & 11.5 & 20.4 & 23.6 & 0.0 & 3.8 & 1.0 \\
\hline Indonesia & 3.2 & 6.8 & 9.8 & 0.1 & 0.6 & 0.5 \\
\hline Russia & 1.6 & 2.3 & 2.8 & 0.4 & 0.3 & 0.2 \\
\hline India & 24.2 & 30.5 & 36.0 & 0.7 & 0.5 & 0.6 \\
\hline USA & 10.3 & 18.4 & 25.2 & 0.4 & 17.2 & 17.2 \\
\hline Canada & 6.2 & 7.3 & 8.2 & 0.2 & 1.7 & 0.3 \\
\hline Mexico & 0.5 & 1.0 & 1.4 & 0.1 & 0.3 & 0.3 \\
\hline Brazil & 0.9 & 2.3 & 3.8 & 0.0 & 0.6 & 0.6 \\
\hline South Africa & 0.0 & 0.1 & 0.1 & 0.0 & 0.0 & 0.0 \\
\hline UK \& Ireland & 4.0 & 7.0 & 9.1 & 0.3 & 9.1 & 8.2 \\
\hline $\begin{array}{l}\text { Northern } \\
\text { Europe }\end{array}$ & 1.6 & 4.3 & 6.4 & 0.0 & 3.5 & 3.5 \\
\hline $\begin{array}{l}\text { Central } \\
\text { Europe } \\
\text { (North) }\end{array}$ & 14.8 & 23.4 & 31.4 & 0.1 & 7.2 & 10.9 \\
\hline $\begin{array}{l}\text { Central } \\
\text { Europe } \\
\text { (South) }\end{array}$ & 4.1 & 6.5 & 7.9 & 0.1 & 5.2 & 1.9 \\
\hline $\begin{array}{l}\text { Southern } \\
\text { Europe }\end{array}$ & 1.5 & 3.0 & 4.5 & 0.3 & 3.3 & 3.0 \\
\hline Australasia & 0.5 & 1.2 & 1.8 & 0.1 & 1.1 & 0.8 \\
\hline $\begin{array}{l}\text { Rest of South } \\
\text { Asia }\end{array}$ & 16.3 & 23.2 & 30.8 & 0.4 & 0.8 & 1.2 \\
\hline $\begin{array}{l}\text { Rest of } \\
\text { sub-Saharan } \\
\text { Africa }\end{array}$ & 1.5 & 2.3 & 3.3 & 0.1 & 0.1 & 0.2 \\
\hline Rest of Europe & 0.8 & 1.1 & 1.4 & 0.4 & 0.5 & 0.3 \\
\hline $\begin{array}{l}\text { Rest of } \\
\text { South-east } \\
\text { Asia }\end{array}$ & 41.8 & 82.0 & 101.5 & 1.2 & 6.6 & 2.4 \\
\hline $\begin{array}{l}\text { Rest of Former } \\
\text { USSR }\end{array}$ & 0.6 & 0.9 & 1.3 & 0.0 & 0.0 & 0.1 \\
\hline $\begin{array}{r}\text { Middle East \& } \\
\text { North Africa }\end{array}$ & 6.8 & 10.1 & 13.2 & 1.0 & 1.6 & 1.7 \\
\hline $\begin{array}{l}\text { Centr. } \\
\text { America \& } \\
\text { Caribbean }\end{array}$ & 0.2 & 0.4 & 0.7 & 0.0 & 0.1 & 0.1 \\
\hline $\begin{array}{l}\text { Rest of South } \\
\text { America }\end{array}$ & 20.3 & 24.2 & 28.2 & 0.1 & 0.4 & 0.3 \\
\hline WORLD & 242 & 385 & 486 & 11 & 75 & 64 \\
\hline
\end{tabular}

Source: DIVA model output (summations across regions and damage categories are authors' calculations, as are the translation of the number of migrants into dollar values)

${ }^{a}$ Explanatory note: Whilst cumulative migration in high SLR scenarios is always higher, this research takes the average values for 2070s, 2080s and 2090s. In some high SLR cases, e.g. China, much migration has already occurred in earlier decades, so the additional migration in these three decades is lower in the high SLR scenarios than the A1B scenario 


\subsection{The Climate Assessment General Equilibrium (CAGE) Model}

The Climate Assessment General Equilibrium (CAGE) model is a static, multi-region, multisector world CGE model based on the Global Trade Analysis Project (GTAP) database version 8 (Narayanan et al. 2012) as its primary data source. As explained further in this section, the model follows standard CGE practice. The full model description and mathematical model statement is provided in the "Appendix".

The CGE analysis follows a static comparative approach (as in e.g. Aaheim et al. 2012; Ciscar et al. 2012), estimating the counterfactual of future SLR (simulated in the 2080s) occurring under the current socioeconomic conditions. Therefore, the SLR future scenarios are shocking the current economy (base year of the model, 2007), without considering that there will be economic growth and demographic change from now to the end of the century. As a consequence, the estimated economic impacts represent a level shift or one-off change in welfare or GDP, and not a change in the growth rates. However, since SLR damage and capital growth are both expected to occur incrementally between 2007 and the 2080s, special consideration is given to the correct calculation of the shock to capital stock (see explanation below).

The GTAP database provides input-output tables for 129 countries/regions (covering all countries) and 57 commodity categories. For this analysis, production has been aggregated to 19 sectors. ${ }^{9}$ The choice of regional aggregation ( 25 regions) was decided according to the following criteria. Firstly, the major individual countries in the climate negotiations have been included separately; therefore Brazil, Canada, China, India, Indonesia, Japan, Korea, Mexico, Russia, South Africa and the USA are included individually. The European Union has been split into five regions: UK and Ireland, Northern Europe, Central Europe (North), Central Europe (South) and Southern Europe. ${ }^{10}$ The remaining regions have been split geographically and are Australasia, Rest of South Asia, Rest of sub-Saharan Africa, Rest of Europe, Rest of South-East Asia, Rest of Former Soviet Union, Middle East \& North Africa, Central America \& Caribbean and South America. All regions are linked through endogenous bilateral trade.

Regarding the closure roles of the CGE model, it is assumed that labour and capital can move between sectors within a country, but they are immobile across regions (see "Appendix" for more details).

\subsection{Modelling the Impacts of SLR in a CGE Framework}

The two main categories of damages (Table 1) have been interpreted as three kinds of damage shocks: damage from forced migration, damage to current consumption (other than from migration) and damage to the capital stock. The forced migration damage is interpreted in the CAGE model as an increase in obliged consumption, which means that the expenditure associated with forced migration is included as part of GDP, but not part of welfare (equivalent

\footnotetext{
9 The sectors are coal, gas, petroleum, crude oil, electricity, construction, chemicals, agriculture, crops, forest, metals, other energy intensive industries, electronic equipment, transport equipment, other equipment, consumer goods, transport, market services and non-market services.

10 The same disaggregation was used for the PESETA project (Ciscar et al. 2011). Precisely, the categories are:

UK and Ireland: United Kingdom and Ireland

Northern Europe: Denmark, Estonia, Finland, Latvia, Lithuania and Sweden

Central Europe (North): Belgium, Germany, Luxembourg, the Netherlands and Poland

Central Europe (South): Austria, Czech Republic, France, Hungary, Romania, Slovak Republic and Slovenia Southern Europe: Bulgaria, Cyprus, Greece, Italy, Malta, Portugal and Spain.
} 
variation). ${ }^{11}$ Therefore, the obliged consumption implies a welfare loss, as consumption is allocated to (compulsory) migration instead of other purposes. In order to estimate the number of migrants in one year in the 2080s, the average value is taken for the 2070s, 2080s and 2090s. This smoothes the variation noted in some regions across these decades. (See also explanatory note to Table 1 .)

The remaining sources of damage costs are sea floods, river floods, land loss and salinisation, of which the largest is sea floods in all regions except Canada. We use the damage estimates for the 2080s. Such damages are interpreted as partially impacting current expenditure, which is modelled as change in obliged consumption (similar to the migration shock), and partially impacting the capital stock (see below for methodology). Evidence on how to split the damages between the two impact types can be found in studies such as Floodsite (2006), which inter alia cites a study about floods in Saxony, where the majority of economic damage from flooding is to buildings and infrastructure (i.e. capital stock), rather than to household goods, crops or livestock (note however, emergency costs are not reported). Some damage to buildings and infrastructure will be repaired (a current expenditure) and others will either reduce the capital stock or redirect capital investment which would have been produced elsewhere (also leading to a net reduction in capital).

As the appropriate share of damages that affects capital is uncertain, we choose a central scenario of $30 \%$ for capital loss, and then perform sensitivity analysis for a lower $(15 \%)$ and higher share of capital (45\%). For our central case then, $70 \%$ of the value of these damages is accounted for as an increase in obliged consumption, which is included in GDP, but not in welfare.

An important issue arises here regarding how to compute the impact on capital stock. DIVA estimates the damages for each year from now until 2100. Given the capital endowment of an economy is a stock variable, we have computed the cumulative damage to capital stock that would occur by the 2080s. As a consequence, to calculate the cumulative damage from the reduction in capital stock (computed as the percentage reduction in capital stock projected for the year 2085), we take the annual share of the damage to the capital stock, depreciated over time (at $5 \%$ annually).

It should be noted that the assumption on the projected growth of capital stock plays a major role in the overall damage estimate. The projected growth path for regional capital stock (in the absence of SLR) is taken from the MaGE macroeconometric model projections (Fouré et al. 2012), which has estimates until 2050. These estimates have been extended until 2085 using the exponential growth path for 2021-2050, and then the average annual growth rate between 2007 (the base year of the model) and 2085 can be readily calculated. The precise calculation for the percentage loss of capital is given by:

$$
K L_{r}=\frac{\left(\alpha \times \sum_{t}\left((1-\delta)^{2085-t} \times D_{r, t}\right)\right)}{\left(K 0_{r} \times\left(1+g k_{r}\right)^{78}\right)}
$$

where KL: percent loss of capital stock; $\alpha$ : share of damage to capital $\delta$ : depreciation rate; D: damage cost; K0: base year capital stock; gk: growth rate of capital stock in absence of SLR; the sets are $r$ for region and $t$ for year.

The denominator computes the projected capital stock if there was no SLR. Note that capital stock growth is compounded over 78 years, which covers the period from the base year of the model, 2007, until 2085.

11 One could consider that forced un-planned migration could result in production losses with labour being temporarily unemployed or underemployed. However, if future migrants are given warning of the need to move, and so can plan new employment and so on, then production losses would not be expected to be large. 
The resulting capital losses are reported below in Table 2 . As can be seen, the majority of regions face losses of capital of $<1 \%$, even in the High SLR scenario only 5 regions out of 25 are exceptions. The numerator calculates the cumulative capital loss, which is the result of the aggregation of the flow of the depreciated damage costs (in excess of the damage cost of no SLR ${ }^{12}$ ) times the share of damage to the capital stock.

\section{Results}

This section presents the two main sets of results regarding GDP and welfare changes. It also presents a sensitivity analysis exercise to one of the parameters used in the implementation of the SLR shock into the CAGE model.

GDP measures the impact of SLR on economic production; however it does not capture the full consequences for household welfare. Therefore we also report the impact on welfare (equivalent variation) for households. Recall that while direct expenditure on forced migration and repairs are recorded as part of GDP, it reduces welfare since the spending is compulsory. Therefore, GDP changes are mainly driven by the shock to the capital stock, while equivalent variation changes are more closely related to the current consumption shocks.

\subsection{Main Scenarios}

The results for the three main scenarios are presented in terms of GDP losses (Table 3) and equivalent variation (Table 4).

The global GDP losses rise from $0.15 \%$ under the A1B scenario to $0.50 \%$ under the High scenario, with large regional disparities. Under the A1B scenario, the region with the largest GDP loss is Central Europe (North) with $0.61 \%$ (which could be expected, as it is the region with the highest percentage capital loss, Table 2), followed by Rest of South-East Asia with $0.37 \%$. Most regions experience fairly small percentage shocks for this scenario, though one notes that the absolute values of the shocks are often substantial. As anticipated, all regions experience higher GDP losses for higher SLR scenarios. In the Rahm scenario, which considers sea levels rising towards $1.4 \mathrm{~m}$ by the end of the century, the two most affected regions (again Rest of South-East Asia and Central Europe North) experience GDP losses above $1 \%$.

One can also identify a second tier of affected regions that experience losses around 0.5$0.6 \%$ of GDP, namely Japan, Korea and Northern Europe. The same pattern of most-affected regions continues in the High scenario with the values rising further, up to a maximum of $1.72 \%$ of GDP in Central Europe North. At the other end of the scale, one can note those regions left nearly unaffected by SLR. Even in the High scenario, Mexico, South Africa and Rest of Former Soviet Union show less than 0.02\% GDP losses, and Russia, sub-Saharan Africa and Central America \& Caribbean show less than $0.07 \%$ GDP losses.

The percentage loss of equivalent variation is shown in Table 4 and also graphically for the High scenario in Fig. 1. The percentage loss is higher than GDP alone (which does not distinguish between obliged and non-obliged consumption), with world losses of $0.54 \%$ for the A1B scenario, rising to $1.91 \%$ for the High scenario. The regional composition of the damages is also altered. Regarding the A1B scenario, Rest of South-East Asia now shows the largest losses, but particularly noteworthy is that China shows the second largest losses at $2.18 \%$ of equivalent variation, and South Asia also shows high losses at $0.98 \%$ (the 5 th

12 DIVA also calculates costs arising from no change in SLR, as there would still be, for example, storm damage. The costs here are only those above this level. 
Table 2 Percentage capital losses entered into the CAGE model (median SLR by 2085 of scenario in brackets)

\begin{tabular}{|c|c|c|c|}
\hline Region & $\mathrm{A} 1 \mathrm{~B}(0.47 \mathrm{~m})$ & RAHM (1.12 m) & $\operatorname{High}(1.75 \mathrm{~m})$ \\
\hline China & 0.08 & 0.18 & 0.27 \\
\hline Japan & 0.49 & 1.21 & 1.73 \\
\hline Korea & 0.42 & 1.08 & 1.42 \\
\hline Indonesia & 0.12 & 0.47 & 0.82 \\
\hline Russia & 0.04 & 0.06 & 0.09 \\
\hline India & 0.05 & 0.12 & 0.18 \\
\hline USA & 0.28 & 0.57 & 0.90 \\
\hline Canada & 0.17 & 0.36 & 0.55 \\
\hline Mexico & 0.01 & 0.04 & 0.07 \\
\hline Brazil & 0.03 & 0.13 & 0.25 \\
\hline South Africa & 0.01 & 0.02 & 0.03 \\
\hline UK \& Ireland & 0.31 & 0.62 & 0.95 \\
\hline Northern Europe & 0.34 & 1.09 & 1.86 \\
\hline Central Europe (North) & 1.26 & 2.12 & 3.41 \\
\hline Central Europe (South) & 0.23 & 0.47 & 0.69 \\
\hline Southern Europe & 0.18 & 0.36 & 0.60 \\
\hline Australasia & 0.07 & 0.17 & 0.28 \\
\hline Rest of South Asia & 0.13 & 0.39 & 0.71 \\
\hline Rest of sub-Saharan Africa & 0.01 & 0.03 & 0.05 \\
\hline Rest of Europe & 0.20 & 0.31 & 0.43 \\
\hline Rest of South-east Asia & 0.56 & 1.69 & 2.43 \\
\hline Rest of Former USSR & 0.02 & 0.05 & 0.08 \\
\hline Middle East \& North Africa & 0.06 & 0.14 & 0.23 \\
\hline Central America \& Caribbean & 0.01 & 0.04 & 0.07 \\
\hline Rest of South America & 0.18 & 0.48 & 0.84 \\
\hline
\end{tabular}

hardest hit region). These two regions experience high damages from current expenditure and migration, though the percentage capital loss is relatively small, hence the fact that neither were among the regions with the largest GDP losses. The regional pattern of damages is approximately maintained into the high SLR scenarios. In the High scenario, Rest of SouthEast Asia shows a huge $12.91 \%$ loss, followed by China (5.63\%) and South Asia $(5.20 \%)$. The less affected regions are South Africa, Mexico and Russia, who experience equivalent variation losses in a range between 0.1 and $0.3 \%$. The values for the High scenario are mapped in Fig. 1, which more clearly shows the geographical distribution of the impacts. Note that the impacts are calculated as a share of equivalent variation at the level of the 25 regions (not individual countries). ${ }^{13}$

\subsection{Sensitivity Analysis}

Tables 5 and 6 report the GDP and welfare changes, respectively, for the sensitivity analysis regarding the share of the sea floods damage that affects capital stock. While in the standard

13 For example, inland countries such as Austria, Mongolia and Paraguay are not directly affected by sea-level rise. For them, the damages shown in Fig. 1 are largely due to their aggregation within a larger region (though these countries will still be affected to some extent due to trade effects). 
Table 3 GDP-percentage loss by scenario (median SLR by 2085 of scenario in brackets)

\begin{tabular}{|c|c|c|c|}
\hline Region & $\mathrm{A} 1 \mathrm{~B}(0.47 \mathrm{~m})$ & RAHM (1.12 m) & $\operatorname{High}(1.75 \mathrm{~m})$ \\
\hline China & -0.10 & -0.21 & -0.30 \\
\hline Japan & -0.21 & -0.53 & -0.75 \\
\hline Korea & -0.22 & -0.57 & -0.74 \\
\hline Indonesia & -0.08 & -0.32 & -0.55 \\
\hline Russia & -0.03 & -0.04 & -0.06 \\
\hline India & -0.04 & -0.09 & -0.13 \\
\hline USA & -0.08 & -0.17 & -0.27 \\
\hline Canada & -0.08 & -0.17 & -0.24 \\
\hline Mexico & 0.00 & -0.01 & -0.01 \\
\hline Brazil & -0.02 & -0.07 & -0.13 \\
\hline South Africa & 0.00 & -0.01 & -0.02 \\
\hline UK \& Ireland & -0.15 & -0.35 & -0.49 \\
\hline Northern Europe & -0.18 & -0.61 & -1.00 \\
\hline Central Europe (North) & -0.61 & -1.07 & -1.72 \\
\hline Central Europe (South) & -0.12 & -0.28 & -0.37 \\
\hline Southern Europe & -0.10 & -0.21 & -0.34 \\
\hline Australasia & -0.03 & -0.09 & -0.13 \\
\hline Rest of South Asia & -0.09 & -0.28 & -0.52 \\
\hline Rest of sub-Saharan Africa & -0.01 & -0.03 & -0.05 \\
\hline Rest of Europe & -0.09 & -0.14 & -0.19 \\
\hline Rest of South-east Asia & -0.37 & -1.12 & -1.57 \\
\hline Rest of Former USSR & 0.00 & -0.01 & -0.01 \\
\hline Middle East \& North Africa & -0.04 & -0.10 & -0.16 \\
\hline Central America \& Caribbean & -0.01 & -0.03 & -0.05 \\
\hline Rest of South America & -0.10 & -0.28 & -0.48 \\
\hline World & -0.15 & -0.33 & -0.50 \\
\hline
\end{tabular}

case a $30 \%$ share is assumed (the rest of the damage affecting current expenditures), the two variants consider lower and higher shares (15 and 45\%). The results for the High scenario are shown, as the consequences of changing the shares for the A1B and Rahm scenarios are similar.

For all regions, the lower share of damage to capital lowers the GDP loss, and the higher share raises the GDP loss, as expected. The one exception is the Rest of the Former USSR, for which the absolute numbers are very small, especially in the higher share case. The largest percentage changes are for Japan and the USA, which both fall by $49 \%$ in the lower share scenario. The unweighted average of the percentage falls is $-40 \%$ in the lower share scenario, and $+40 \%$ in the higher share scenario. The largest percentage point changes are for Central Europe (North) $(-0.79 \mathrm{pp} ;+0.80 \mathrm{pp})$ followed by Rest of South-East Asia $(-0.63 \mathrm{pp}$; $+0.64 \mathrm{pp})$.

The percentage changes in equivalent variation are smaller than those found for GDP. This is expected as both capital and current consumption damages have a major impact on equivalent variation, whereas capital damage has a much larger impact on GDP. Indeed whether capital or current damage has a larger impact depends on the characteristics of the 
Table 4 Equivalent variation-percentage loss by scenario (median SLR by 2085 of scenario in brackets)

\begin{tabular}{|c|c|c|c|}
\hline Region & $\mathrm{A} 1 \mathrm{~B}(0.47 \mathrm{~m})$ & RAHM (1.12 m) & $\operatorname{High}(1.75 \mathrm{~m})$ \\
\hline China & -2.18 & -4.14 & -5.63 \\
\hline Japan & -0.56 & -1.70 & -2.16 \\
\hline Korea & -1.28 & -3.96 & -4.22 \\
\hline Indonesia & -0.54 & -2.20 & -3.44 \\
\hline Russia & -0.17 & -0.21 & -0.23 \\
\hline India & -0.77 & -1.52 & -2.22 \\
\hline USA & -0.18 & -0.58 & -0.79 \\
\hline Canada & -0.26 & -0.74 & -0.78 \\
\hline Mexico & -0.03 & -0.14 & -0.21 \\
\hline Brazil & -0.08 & -0.40 & -0.66 \\
\hline South Africa & -0.03 & -0.08 & -0.12 \\
\hline UK \& Ireland & -0.37 & -1.29 & -1.58 \\
\hline Northern Europe & -0.57 & -2.56 & -3.68 \\
\hline Central Europe (North) & -1.38 & -2.71 & -4.24 \\
\hline Central Europe (South) & -0.33 & -0.96 & -1.04 \\
\hline Southern Europe & -0.23 & -0.61 & -0.88 \\
\hline Australasia & -0.13 & -0.54 & -0.66 \\
\hline Rest of South Asia & -0.98 & -3.00 & -5.20 \\
\hline Rest of sub-Saharan Africa & -0.15 & -0.33 & -0.54 \\
\hline Rest of Europe & -0.34 & -0.48 & -0.59 \\
\hline Rest of South-east Asia & -3.30 & -10.42 & -12.91 \\
\hline Rest of Former USSR & -0.11 & -0.25 & -0.37 \\
\hline Middle East \& North Africa & -0.30 & -0.66 & -0.96 \\
\hline Central America \& Caribbean & -0.07 & -0.19 & -0.33 \\
\hline Rest of South America & -0.46 & -1.31 & -2.14 \\
\hline World & -0.54 & -1.40 & -1.91 \\
\hline
\end{tabular}

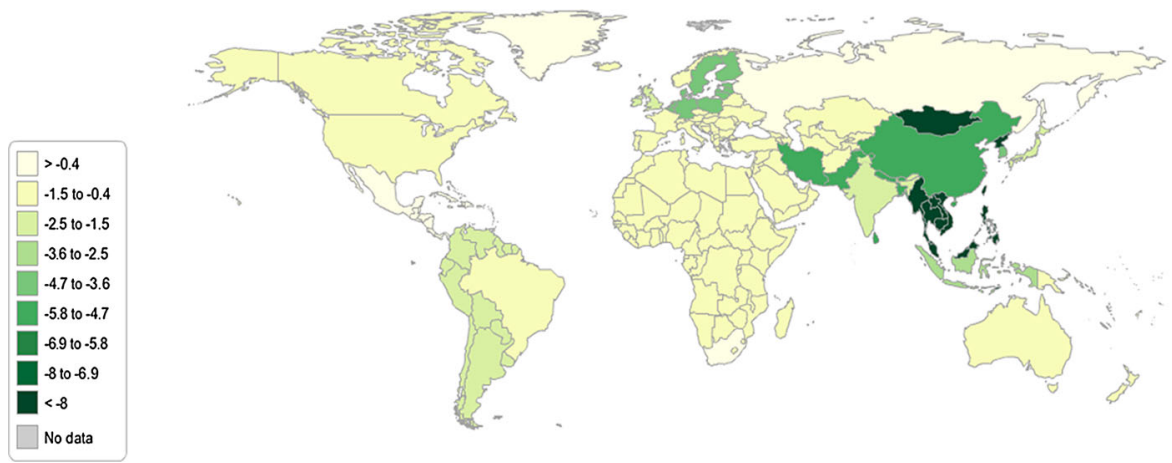

Fig. 1 Equivalent variation - percentage loss in High scenario (1.75 $\mathrm{m}$ rise in median SLR by 2085)

region, which is why some regions show a higher welfare loss for a lower capital damage share (and a lower loss for a higher share) and other regions show the opposite. For the lower share scenario, the largest percentage increase in damage is for Russia (36\%) and the 
Table 5 GDP - percentage loss by share of damage to capital (High scenario only)

\begin{tabular}{|c|c|c|c|}
\hline Region & $\begin{array}{l}\text { High }(1.75 \mathrm{~m}) \\
\text { Low } \mathrm{K} \text { damage } \\
\alpha=0.15\end{array}$ & $\begin{array}{l}\text { High }(1.75 \mathrm{~m}) \\
\text { Stnd } \mathrm{K} \text { damage } \\
\alpha=0.30\end{array}$ & $\begin{array}{l}\text { High }(1.75 \mathrm{~m}) \\
\text { High } \mathrm{K} \text { damage } \\
\alpha=0.45\end{array}$ \\
\hline China & -0.26 & -0.30 & -0.34 \\
\hline Japan & -0.39 & -0.75 & -1.12 \\
\hline Korea & -0.39 & -0.74 & -1.09 \\
\hline Indonesia & -0.31 & -0.55 & -0.78 \\
\hline Russia & -0.04 & -0.06 & -0.08 \\
\hline India & -0.09 & -0.13 & -0.17 \\
\hline USA & -0.14 & -0.27 & -0.40 \\
\hline Canada & -0.13 & -0.24 & -0.35 \\
\hline Mexico & -0.01 & -0.01 & -0.02 \\
\hline Brazil & -0.08 & -0.13 & -0.19 \\
\hline South Africa & -0.01 & -0.02 & -0.03 \\
\hline UK \& Ireland & -0.30 & -0.49 & -0.69 \\
\hline Northern Europe & -0.58 & -1.00 & -1.43 \\
\hline Central Europe (North) & -0.93 & -1.72 & -2.52 \\
\hline Central Europe (South) & -0.21 & -0.37 & -0.54 \\
\hline Southern Europe & -0.18 & -0.34 & -0.50 \\
\hline Australasia & -0.08 & -0.13 & -0.19 \\
\hline Rest of South Asia & -0.29 & -0.52 & -0.75 \\
\hline Rest of sub-Saharan Africa & -0.03 & -0.05 & -0.06 \\
\hline Rest of Europe & -0.10 & -0.19 & -0.28 \\
\hline Rest of South-east Asia & -0.94 & -1.57 & -2.21 \\
\hline Rest of Former USSR & -0.01 & -0.01 & 0.00 \\
\hline Middle East \& North Africa & -0.09 & -0.16 & -0.24 \\
\hline Central America \& Caribbean & -0.03 & -0.05 & -0.07 \\
\hline Rest of South America & -0.28 & -0.48 & -0.68 \\
\hline World & -0.28 & -0.50 & -0.72 \\
\hline
\end{tabular}

largest percentage fall is for Central Europe (North) (31\%). The largest percentage point increase is for China $(0.77 \mathrm{pp})$ and the largest percentage point fall is for Central Europe (North) (1.31 pp). The unweighted average of the absolute percentage differences is $16 \%$ for the lower share scenario.

One notes a tendency for higher damage estimates for relatively rich regions when the assumed capital intensity is higher (as is the case for Japan, Korea, USA, Canada, all European regions and Australasia); whereas the opposite is often, though not always, true for relatively poor regions. This is partially driven by the differences in the economies' capital-to-labour ratios.

We conclude from this sensitivity analysis that the choice of the share of damages going to capital can influence the size of regional results significantly, and for equivalent variation can do so in different directions. More systematic research is needed also regarding other parameters and structural features of the models. Nevertheless, even under the large parameter changes entered here for the sensitivity analysis, the overall picture is maintained: the same 
Table 6 Equivalent variation-percentage loss by share of damage to capital (High scenario only)

\begin{tabular}{|c|c|c|c|}
\hline Region & $\begin{array}{l}\text { High }(1.75 \mathrm{~m}) \\
\text { Low } \mathrm{K} \text { damage } \\
\alpha=0.15\end{array}$ & $\begin{array}{l}\text { High }(1.75 \mathrm{~m}) \\
\text { Stnd } \mathrm{K} \text { damage } \\
\alpha=0.30\end{array}$ & $\begin{array}{l}\operatorname{High}(1.75 \mathrm{~m}) \\
\text { High } \mathrm{K} \text { damage } \\
\alpha=0.45\end{array}$ \\
\hline China & -6.41 & -5.63 & -4.86 \\
\hline Japan & -1.54 & -2.16 & -2.78 \\
\hline Korea & -4.03 & -4.22 & -4.42 \\
\hline Indonesia & -3.49 & -3.44 & -3.39 \\
\hline Russia & -0.31 & -0.23 & -0.15 \\
\hline India & -2.52 & -2.22 & -1.93 \\
\hline USA & -0.61 & -0.79 & -0.97 \\
\hline Canada & -0.64 & -0.78 & -0.93 \\
\hline Mexico & -0.23 & -0.21 & -0.19 \\
\hline Brazil & -0.62 & -0.66 & -0.69 \\
\hline South Africa & -0.10 & -0.12 & -0.15 \\
\hline UK \& Ireland & -1.31 & -1.58 & -1.85 \\
\hline Northern Europe & -2.96 & -3.68 & -4.41 \\
\hline Central Europe (North) & -2.93 & -4.24 & -5.58 \\
\hline Central Europe (South) & -0.76 & -1.04 & -1.32 \\
\hline Southern Europe & -0.62 & -0.88 & -1.15 \\
\hline Australasia & -0.59 & -0.66 & -0.72 \\
\hline Rest of South Asia & -5.66 & -5.20 & -4.74 \\
\hline Rest of sub-Saharan Africa & -0.65 & -0.54 & -0.43 \\
\hline Rest of Europe & -0.46 & -0.59 & -0.73 \\
\hline Rest of South-east Asia & -13.58 & -12.91 & -12.25 \\
\hline Rest of Former USSR & -0.47 & -0.37 & -0.27 \\
\hline Middle East \& North Africa & -0.96 & -0.96 & -0.95 \\
\hline Central America \& Caribbean & -0.33 & -0.33 & -0.33 \\
\hline Rest of South America & -2.05 & -2.14 & -2.24 \\
\hline World & -1.67 & -1.91 & -2.14 \\
\hline
\end{tabular}

regions are the most affected and the broad magnitude of the impact remains, especially in terms of welfare.

\section{Conclusion}

This paper uses the DIVA model estimates of direct impacts of sea-level rise and the CAGE world CGE model to estimate the economy-wide implications of various SLR scenarios in the absence of public adaptation. There are two new elements of the analysis compared to the literature. First, the study considers a wider range of SLR (including extreme SLR). The SLR impacts under the A1B scenario (with $0.47 \mathrm{~m}$ SLR by the 2080 s, relative to pre-industrial levels) are compared to other scenarios that consider the influence of major ice sheet melting, which yield a 1.12 and $1.75 \mathrm{~m}$ SLR by the $2080 \mathrm{~s}$.

A second novel aspect of this research is that it models a range of types of damage shocks, which has not been previously considered in a global assessment. In particular, some 
previous assessments have only modelled the SLR economic impacts due to land loss, which is indeed a small share of the overall direct economic damage. Other damage categories, such as migration costs and sea floods costs, are much more significant, and their influence on economic activity and welfare have been explicitly considered in this article. Sea floods costs and other costs are decomposed into two main damage categories in the CGE model: current consumption losses and capital losses.

By incorporating 25 world regions in the assessment, there is also more detail of the regional differences than previous world-wide studies. The simulation results of this article can be potentially used to underpin the regional damages estimates of stylised regional integrated assessment models (e.g. Hof et al. 2013).

Regarding the results of the analysis, it is particularly notable that the regions that are heavily impacted in terms of GDP, which is driven by the percentage cumulative loss of capital, are not always the same as those heavily impacted in terms of welfare (equivalent variation), which is driven by current consumption costs and forced migration.

The impact estimates are relatively large compared with those of previous studies, even for the case of lower SLR. For example, Bosello et al. (2012) find damages for non-EU countries of around $0.03 \%$ of GDP for a sea-level rise similar to the A1B scenario here without adaptation, whereas we find approximately $0.15 \%$ of GDP: five times as large. This is mainly due to the fact that a broader definition of impacts is considered in the analysis with the inclusion of migration costs and sea floods costs. There is also a large regional variation in economic damages. For instance, regarding welfare losses, while the global loss is estimated to be $1.4 \%$ for the $1.12 \mathrm{~m} \mathrm{SLR}$ case, it can reach more than $10 \%$ in the Rest of South-east Asia and $4 \%$ in China. Thus aggregate impact estimates mask considerable regional variability. The regional pattern can be useful for designing regional public adaptation policies.

A number of caveats should be raised. First, the results of this preliminary assessment should not be interpreted as a projection or forecast of the likely impact of SLR. This article illustrates the application of one methodology integrating direct cost estimates from a specific coastal impact model (DIVA) into a particular economic model (CAGE). While we hope it is informative, there are many uncertainties in the modelling exercise that should be considered. They range from the uncertainty about the extent of future global SLR and its regional pattern to the many uncertainties in the biophysical and economic models. The model uncertainties regard both their structural features as outlined in the mathematical equations and to their parameterisation. Future research should conduct further sensitivity analyses on these sources of uncertainties. Moreover, when considering the nature and level of impacts, results from local and regional case studies should also be taken into account.

\section{Appendix: Model Description and Mathematical Model Statement of the CAGE Model}

\section{Model Description}

This Appendix outlines the behaviour and interaction of the economic agents in the CAGE model, followed by the mathematical model statement.

Producers seek to maximise profits subject to their production technology and the cost of inputs. The production technology is modelled using a nested constant elasticity of substitution (CES) function which is summarised in Fig. 2 below.

As shown, output is produced by combining capital (K) and labour $(\mathrm{L})$ with energy $(\mathrm{E})$ and other intermediate inputs. All combinations of inputs are treated as imperfect substitutes, 


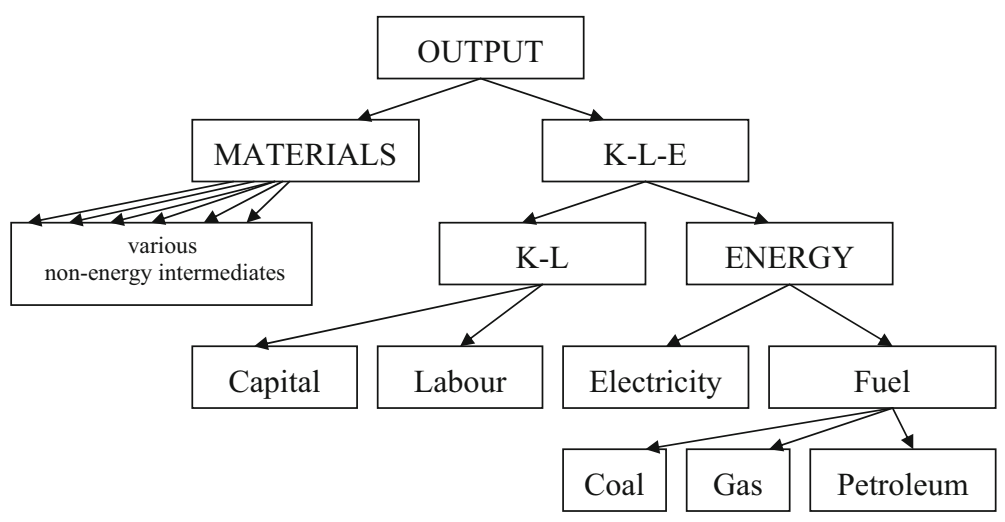

Fig. 2 Production structure in the CAGE model. Note: K-L-E refers to the capital-labour-energy bundle and $\mathrm{K}-\mathrm{L}$ to the capital-labour bundle

as governed by CES functions (though some are given low elasticity values to reflect low levels of substitutability).

All commodities enter the marketplace. Production from each country can be sold either within that country or exported. Similarly, the purchase of goods and services can be either of domestic production or imports. Total domestic demand consists of that from households, government, investment, intermediate inputs, and inputs for transport margins used for trade. The extent to which this domestic demand is satisfied by imports or domestic production is governed by a two-level constant elasticity of substitution function reflecting the imperfect substitutability at both levels. On the lower level, imports from different regions are combined, and on the upper level, the composite import commodity is combined with domestic production (the Armington function, Armington 1969).

The economic institutions included in the model are households, government, firms and the rest of the world. Households purchase marketed commodities at market prices, meaning that the prices include commodity taxes. Households maximise their utility or well-being based on their preferences and the relative prices of goods and services, subject to their income constraints. Household consumption also has a nested structure, with households first choosing between energy and non-energy commodities and then on consumption within these categories. Substitutability within each nest is determined by a constant elasticity of substitution function. ${ }^{14}$

There are general constraints to the system (which are not directly considered by any of the particular economic agents). The zero profit constraint in production is imposed as firms are assumed to operate in a competitive environment. There are also zero profit constraints on domestic economic institutions - households, governments and investment—which mean that all income to institutions must be accounted for with either spending or saving. With respect to imports and transport margins, the zero profit conditions imply that their prices are also constrained to match their costs, inclusive of margins and taxes, as appropriate.

The macroeconomic closure rules govern the savings-investment behaviour, aggregate government finances, the behaviour of factor markets and the trade balance between each country and the rest of the world. The savings-investment closure maintains a constant volume of investment, and any change in the price of investment goods is adjusted for by changing the

14 The structure of household consumption and the elasticity values are chosen with reference to the MIT EPPA model (Paltsev et al. 2005). 
value of household savings. The government closure allows public consumption to be flexible in terms of quantity, then any additional revenue to government raises government income, and hence raises government expenditure. In that case, government consumption is modelled with a Leontief function, i.e. an increase (fall) in government expenditure proportionally increases (decreases) consumption of all commodities. The factor-market closure fixes the aggregate volume of both capital and labour at the regional level. Both capital and labour can move between sectors, however capital and labour are immobile across regions. Thus, returns to capital and wage rate of labour adjust to clear the market, and the wage and capital prices are region specific. The rest-of-the-world closure fixes the current account balance between regions at the benchmark level, with prices adjusting to ensure that all production from each region is either consumed domestically or exported.

Mathematical Model Statement

Sets

i, j commodities

f factors

$\mathrm{r}, \mathrm{s}$ regions

\section{Parameters}

* Benchmark parameters, consumption related

c0(r) benchmark total consumption

cd0(i,r) benchmark household demand

ch0(i,r) benchmark minimum consumption

pc0(i,r) benchmark consumption price

tc(i,r) final consumption tax

tc_vat(i,r) vat tax rate final consumption

tc_oth(i,r) other taxes rate final consumption

$\mathrm{ks} 0(\mathrm{r})$ benchmark capital supply

ls0(1,r) benchmark labor supply

ks(r) capital supply

1s(1,r) labour supply

htax0(r) benchmark transfer

* Benchmark parameters, public consumption related

$\mathrm{g} 0(\mathrm{r})$ benchmark total govt consumption

gd0(i,r) benchmark government demand

pg0(i,r) benchmark government price

$\operatorname{tg}(\mathrm{i}, \mathrm{r})$ public consumption tax

* Benchmark parameters, investment related

inv0(r) benchmark total investment

invd0(i,r) benchmark investment demand

pinv0(i,r) benchmark investment input price

tinv(i,r) investment input tax

* Benchmark parameters, production related

y0(i,r) benchmark total output

d0(i,r) benchmark output to dom market 
e0(i,r) benchmark output to exports

$\operatorname{id} 0(\mathrm{i}, \mathrm{j}, \mathrm{r})$ benchmark intermediate input

kd0(i,r) benchmark capital demand

ld0(1,i,r) benchmark labour demand

piO(i,j,r) benchmark intermediate input price

pk0(i,r) benchmark capital input price

pl0(l,i,r) benchmark labour input price

ti(i,j,r) intermediate input tax

tk(i,r) capital use tax

tl(l,i,r) labour use tax

to(i,r) output tax

tk0(i,r) benchmark capital use tax

tl0(1,i,r) benchmark labour use tax

to0(i,r) benchmark output tax

tpk(i,r) capital technological progress

tpl(l,i,r) labour technological progress

tpm(i,j,r) material technological progress

* Benchmark parameters, trade related

a0(i,r) benchmark Armington supply

m0(i,r) benchmark imports

d0(i,r) benchmark domestic supply

md0(i,r,s) benchmark bilateral import demand

$\operatorname{mad} 0(\mathrm{i}, \mathrm{j}, \mathrm{r}, \mathrm{s})$ benchmark bilat. tr. margin demand

pmd0(i,r,s) benchmark bilateral import price

pma0(i,r,s) benchmark bilat. tr. margin price

$\operatorname{tm}(\mathrm{i}, \mathrm{r}, \mathrm{s})$ import tax

te(i,r,s) export tax

ma0(i) benchmark transport margin supply

mae0(i,r) bnchmrk exports to transport margin pool

$m t 0(i, r, s)$ benchmark imports of $i$ from $r$ to $s$ incl. margin

$\operatorname{tm}(\mathrm{i}, \mathrm{r}, \mathrm{s})$ import tax

te(i,r,s) export tax

* Benchmark cost

c0_Y(i,r) benchmark unit cost sector i

c0_Ys(i,r) benchmark cost top-level sector i

c0_KLE(i,r) benchmark cost capital-labour-energy nest sector i

c0_KL(i,r) benchmark cost capital-labour cost sector i

c0_L(i,r) benchmark cost labour cost sector i

c0_ENG(i,r) benchmark cost energy nest sector i

c0_ENE(i,r) benchmark cost primary energy nest sector i

c0_ELE(i,r) benchmark cost electricity nest

c0_MAT(i,r) benchmark cost material nest sector i

* Substitution elasticities

sigma_MAT_KLE(i,r) substitution elasticity production: top-level (material vs valueadded-energy bundels)

sigma_MAT(i,r) substitution elasticity production: matrial bundel 
sigma_KLE(i,r) substitution elasticity production: energy vs value-added bundle sigma_KL(i,r) substitution elasticity production: capital vs labor

sigma_ENG(i,r) substitution elasticity production: electricity vs primary energy products

sigma_L(i,r) substitution elasticity production: types of labor

sigma_ENE(i,r) substitution elasticity production: primary energy products sigma_ELE(i,r) substitution elasticity production: electricity nest

* Armington trade

sigma_A(i,r) substitution elasticity Armington: domestic vs import bundle sigma_M(i,r) substitution elasticity Armington: imported products

* Consumption

sigma_C(r) substitution elasticity consumption: top-level

sigma_CENE(r) substitution elasticity consumption: energy nest

sigma_COTH(r) substitution elasticity consumption: other i.e. non-energy

* Government and Investment

sigma_G(r) substitution elasticity government: top-level

sigma_I(r) substitution elasticity investment: top-level

* Value shares

thetaKL_L(i,r) labour share in capital-labour nest of branch i

thetaKL_K(i,r) capital share in capital-labour nest of branch i

thetaL(l,i,r) labour share by type in labour nest of branch $\mathrm{i}$

thetaMAT(j,i,r) value share of commodity $\mathrm{j}$ in sector i material nest

thetaENE(j,i,r) primary energy shares commodity $\mathrm{j}$ in primary energy nest sector $\mathrm{i}$

thetaELE(j,i,r) primary energy shares commodity $\mathrm{j}$ in energy-electricity nest sector $\mathrm{i}$

thetaENG(i,r) share of electricity nest in ENG bundle

thetaKLE(i,r) share of KL nest in KLE bundle

thetaYs(i,r) share of KLE bundle in top level

* consumption

thetaC(r) share of energy commodity nest in total private consumption

thetaCENE(i,r) share of commodity i in energy commodity nest private consumption

thetaCOTH(i,r) share of commodity $\mathrm{i}$ in non-energy commodity nest private consumption

* Government and Investment

thetaG(i,r) share of commodity $i$ in government consumption

thetaI(i,r) share of commodity $i$ in investment consumption

* trade

thetaM(i,r,s) share commodity i produced in $\mathrm{r}$ in imports region $\mathrm{s}$

thetaD(i,r) share domestic produced commodity $i$ in Armington aggregate

thetaT(i,r) share of country $r$ in transport pool commodity $i$

thetaMT(i,j,r,s) share of margin commodity $i$ in import of good $j$ from $r$ to $s$

thetaMM(i,r,s) share of commodity value in imports of commodity $i$ from $r$ to $s$

\section{Variables}

* Activity variables (defined as indexes) Y(i,r) Production index 
$\mathrm{C}(\mathrm{r})$ Consumption expenditure index

GEXP(r) Government expenditure index

M(i,r) Import Index

A(i,r) Armington Index

YT(i) Transport margin Index

INV(r) Investment Index*

* Price variables

PY(i,r) Output price

$\mathrm{PC}(\mathrm{r})$ Consumption price index

PG(r) Government price Index

PM(i,r) Import price

PA(i,r) Armington price

PT(i) Transport margin price

PK(r) Capital price

PL(r) Labour price

PINV(r) Investment price

* Incomes variables

INC_RA(r) Income representative agent

INC_G(r) Income government agent

* Auxiliary variables

LSMULT(r) Multiplier for equal yield (lumps sum tax recycling)

* Variables related to nesting structure, cost indexes

CMV(i,r) Variable for imported commodities

CM_LV (i,r,s) Variable for lower nest of import equation

CYV(i,r) Variable for prod fn: top level KLE vs MAT

CY_KLEV(i,r) Variable for prod fn: second level Capital-Labor-Energy Bundle

CY_MATV(i,r) Variable for prod fn: second level Material bundle

CY_KLV(i,r) Variable for prod fn: third level Capital-Labor Bundle

CY_ENGV(i,r) Variable for prod fn: third level Primary Energy-Electricity Bundle

CY_ENEV(i,r) Variable for prod fn: fourth level Primary Energy Bundle

CY_ELEV(i,r) Variable for prod fn: fourth level Electricity Bundle

C_EXPV(r) Variable for private consumption CES expre fn: energy —other bundle

C_CENEV(r) Variable for private consumption CES expre fn: energy bundle

C_COTHV(r) Variable for private consumption CES expre fn: non-energy bundle

$\operatorname{DEMCV}(\mathrm{i}, \mathrm{r})$ Variable for private demand function

DEMY_YV(j,i,r) Variable for intermediate input demand function

DEMY_LV(i,r) Variable for labour demand function

DEMY_KV(i,r) Variable for capital demand function

DEMM_MV(i,s,r) Variable for demand for imports from $s$ to $r$

DEMM_TV(j,i,s,r) Variable for demand for margins for imports from $\mathrm{s}$ to $\mathrm{r}$

CAV(i,r) Variable for Armington aggtn CES 
Equations

Zero Profit Conditions

Zero profits in production

$$
\left(1-t o_{i, r}\right) \times P Y_{i, r}=C Y V_{i, r}
$$

Zero profits in consumption

$$
P C_{, r}=C_{-} E X P V_{r}
$$

Zero profits in public consumption

$$
P G_{r}=\sum_{m \_i}\left(\text { theta } G_{m \_i, r} \times\left(1+t g_{m \_} i, r\right) \times \frac{P A_{m \_i, r}}{p g 0_{m \_} i, r}\right)
$$

Zero profits in investment

$$
P I N V_{r}=\sum_{m \_i}\left(\text { theta } I_{m \_i, r} \times\left(1+t i n v_{m \_} i, r\right) \times \frac{P A_{m \_i, r}}{p i n v 0_{m \_} i, r}\right)
$$

Zero profits in imports

$$
P M_{i, r}=C M V_{i, r}
$$

Zero profits in Armington aggregation

$$
P A_{i, r}=C A V_{i, r}
$$

Zero profits transport pool

$$
P T_{i}=\prod_{m \_r}\left(P Y_{i, m \_r}^{\text {theta } T_{i, m \_r}}\right)
$$

Imports

Imports (CES aggregation of lower nest)

$$
C M V_{i, r}=\sum_{m_{-} s}\left(\text { theta }_{i, m_{-} s, r} \times C M_{-} L V_{i, m \_s, r}^{1-\text { sigma }_{i, r}}\right)^{1 / 1-\text { sigmaM }_{i, r}}
$$

Lower nest of imports (Leontief aggregation of commodities \& international transport margin)

$$
\begin{array}{r}
C M_{-} L V_{i, r, s}=\text { theta } M M_{i, r, s} \times\left(1+t m_{i, r, s}\right) \times\left(1+t e_{i, r, s}\right) \times \frac{P Y_{i, r}}{p m d 0_{i, r, s}} \\
+\sum_{m_{-} j}\left(\operatorname{theta} M T_{m_{-} j, i, r, s} \times\left(1+t m_{i, r, s}\right) \times \frac{P T_{m_{-} j}}{p m a 0_{i, r, s}}\right)
\end{array}
$$

Demand for imports from region s to region $\mathrm{r}$

$$
D E M M_{-} M V_{i, s, r}=m d 0_{i, s, r} \times M_{i, r} \times\left(C M V_{i, r} / C M_{-} L V_{i, s, r}\right)^{s i g m a \_M_{i, r}}
$$


Demand for margins on imports from region $\mathrm{s}$ to region $\mathrm{r}$

$$
D E M M_{-} T V_{j, i, s, r}=\operatorname{mad}_{j, i, s, r} \times M_{i, r} \times\left(C M V_{i, r} / C M_{-} L V_{i, s, r}\right)^{s i g m a \_M_{i, r}}
$$

Armington aggregation (CES)

$$
\begin{aligned}
C A V_{i, r}= & \left(\operatorname{theta} D_{i, r} \times P Y_{i, r}{ }^{1-s i g m a \_} A_{i, r}\right. \\
& \left.+\left(1-\operatorname{theta} D_{i, r}\right) \times P M_{i, r} 1-\text { sigma_A } A_{i, r}\right)^{1 / 1-s i g m a \_} A_{i, r}
\end{aligned}
$$

\section{Private Consumption}

Expenditure function - top level (energy vs other expenditure)

$$
\begin{aligned}
C_{-} E X P V_{r}=( & \text { theta } C_{r} \times C_{-} C E N E V_{r}{ }^{1-\text { sigma }_{-} C_{r}} \\
& \left.+\left(1-\text { theta }_{r}\right) \times C_{-} C O T H V_{r}{ }^{1-\text { sigma_C }_{r}}\right)^{1 / 1-\text { sigma_C }}
\end{aligned}
$$

Expenditure function-lower level (energy bundle)

$$
\begin{aligned}
C \_C E N E V_{r}= & \left(\sum _ { m \_ i } \left(\text { thetaCENE } m_{-} i, r\right.\right. \\
& \left.\left.\times\left(\left(1+t c_{m_{-} i, r}\right) \times \frac{P A_{m_{-} i, r}}{p c 0_{m_{-} i, r}}\right)^{1-\text { sigma_CENE }_{r}}\right)\right)^{1 / 1-\text { sigma_CENE }_{r}}
\end{aligned}
$$

Expenditure function-lower level (non-energy bundle)

$$
\begin{aligned}
C \_C O T H V_{r}= & \left(\sum _ { m \_ i } \left(\text { thetaCOTH }_{m_{-} i, r}\right.\right. \\
& \left.\left.\times\left(\left(1+t c_{m_{-} i, r}\right) \times \frac{P A_{m_{-} i, r}}{p c 0_{m_{-} i, r}}\right)^{1-\text { sigma_COTH }_{r}}\right)\right)^{1 / 1-\text { sigma_COTH }_{r}}
\end{aligned}
$$

Private demand function A (for $\mathrm{i}=$ energy commodities)

$$
\begin{aligned}
D E M C V_{i, r}= & c d 0_{i, r} \times C_{r} \\
& \times\left[\left(\frac{C_{-} E X P V_{r}}{C_{-} C E N E V_{r}}\right)^{s i g m a_{-} C_{r}} \times\left(\frac{C_{-} C E N E V_{r} \times p c 0_{i, r}}{\left(1+t c_{i, r}\right) \times P A_{i, r}}\right)^{s i g m a_{-} C E N E_{r}}\right]
\end{aligned}
$$

Private demand function B (for $\mathrm{i}$ = non-energy commodities)

$$
\begin{aligned}
D E M C V_{i, r}= & c d 0_{i, r} \times C_{r} \\
& \times\left[\left(\frac{C_{-} E X P V_{r}}{C_{-} C O T H V_{r}}\right)^{\text {sigma_ } C_{r}} \times\left(\frac{C_{-} C O T H V_{r} \times p c 0_{i, r}}{\left(1+t c_{i, r}\right) \times P A_{i, r}}\right)^{s i g m a \_C O T H_{r}}\right]
\end{aligned}
$$




\section{Production}

Production cost function— top level (capital/labour/energy bundle—materials)

$$
\begin{aligned}
& C Y V_{i, r}=c 0 \_Y_{i, r} \times\left(\operatorname{theta} Y s_{i, r} \times C Y \_K L E V_{i, r}^{1-s i g m a \_M A T \_K L E_{i, r}}\right. \\
& \left.+\left(1-\operatorname{theta} s_{i, r}\right) \times C Y \_M A T V_{i, r}^{1-s i g m a \_M A T \_K L E}\right)^{1 / 1-s i g m a \_M A T \_K L E_{i, r}}
\end{aligned}
$$

Production cost function—2nd level (capital/labour bundle—energy)

$$
\begin{aligned}
C Y \_K L E V_{i, r}= & \left(\text { thetaKLE }_{i, r} \times C Y \_K L V_{i, r}^{1-\text { sigma_KLE }_{i, r}}\right. \\
& \left.+\left(1-\text { thetaKLE }_{i, r}\right) \times C Y \_E N G V_{i, r}^{1-s i g m a \_K L E_{i, r}}\right)^{1 / 1-s i g m a \_K L E_{i, r}}
\end{aligned}
$$

Production cost function-2nd level (materials bundle)

$$
\begin{aligned}
& C Y \_M A T V_{i, r}=\left(\sum _ { m _ { - } j } \left(\text { thetaMAT } m_{-} j, i, r\right.\right. \\
& \\
&\left.\left.\left.\times \frac{P A_{m_{-} j, r}}{p i 0_{m_{-} j, i, r}}\right)^{1-\text { sigma }_{-} M A T_{i, r}}\right)\right)^{1 / 1-\text { sigma }_{-} M A T_{i, r}}
\end{aligned}
$$

Production cost function-3rd level (capital-labour)

$$
\begin{aligned}
C Y \_K L V_{i, r}= & \left(\text { theta } K L_{-} K_{i, r} \times\left(\left(1+t k_{i, r}\right) \times \frac{P K_{r}}{p k 0_{i, r}}\right)^{1-s i g m a \_K L_{i, r}}\right. \\
& \left.+ \text { thetaK } L_{-} L_{i, r} \times\left(\left(1+t l_{i, r}\right) \times \frac{P L_{r}}{p l 0_{i, r}}\right)^{1-s i g m a \_K L_{i, r}}\right)^{1 / 1-s i g m a \_K L E_{i, r}}
\end{aligned}
$$

Production cost function-3rd level (energy-electricity)

$$
\begin{aligned}
C Y \_E N G V_{i, r}= & \text { thetaeng }_{i, r} \times C Y \_E L E V_{i, r}^{1-s_{i g m a} E N G_{i, r}} \\
& \left.+\left(1-\text { thetaENG }_{i, r}\right) \times C Y \_E N E V_{i, r}^{1-s i g m a \_E N G_{i, r}}\right)^{1 / 1-\text { sigma_ENG }_{i, r}}
\end{aligned}
$$

Production cost function - 4th level (primary energy bundle)

$$
\begin{aligned}
C Y \_E N E V_{i, r}= & \left(\sum _ { m \_ i } \left(\text { thetaENE } E _ { m _ { - } i , i , r } \left(\left(1+t i_{m_{-} i, i, r}\right)\right.\right.\right. \\
& \left.\left.\left.\times \frac{P A_{m_{-} i, r}}{p i 0_{m_{-} i, i, r}}\right)^{1-s i g m a_{-} E N E_{i, r}}\right)\right)^{1 / 1-s i g m a \_E N E_{i, r}}
\end{aligned}
$$

Production cost function-4th level (electricity bundle)

$$
\begin{aligned}
C Y \_E L E V_{i, r}= & \left(\sum _ { m \_ i } \left(\text { thetaELE } E _ { m _ { - } i , i , r } \left(\left(1+t i_{m_{-} i, i, r}\right)\right.\right.\right. \\
& \left.\left.\left.\times \frac{P A_{m_{-} i, r}}{p i 0_{m_{-} i, i, r}}\right)^{1-s i g m a \_E L E_{i, r}}\right)\right)^{1 / 1-s i g m a \_E L E_{i, r}}
\end{aligned}
$$


Intermediate demand function $\mathrm{A}$ (for $\mathrm{j}=$ electricity)

$$
\begin{aligned}
D E M Y_{-} Y V_{j, i, r}= & i d 0_{j, i, r} \times Y_{i, r}\left\{\left(\frac{C Y V_{i, r}}{c 0_{-} Y_{i, r} \times C Y \_K L E V_{i, r}}\right)^{s i g m a \_M A T_{-} K L E_{i, r}}\right. \\
& \times\left(\frac{C Y \_K L E V_{i, r}}{C Y_{-} E N G V_{i, r}}\right)^{s i g m a_{-} K L E_{i, r}} \times\left(\frac{C Y_{-} E N G V_{i, r}}{C Y \_E L E V_{i, r}}\right)^{s i g m a_{-} E N G_{i, r}} \\
& \times\left(\frac{C Y_{-} E L E V_{i, r} \times p i 0_{j, i, r}}{\left(1+t i_{j, i, r}\right) \times P A_{j, r}}\right)^{s i g m a \_E L E_{i, r}}
\end{aligned}
$$

Intermediate demand function $B$ (for $\mathrm{j}=$ non-electricity energy)

$$
\begin{aligned}
D E M Y \_Y V_{j, i, r}= & i d 0_{j, i, r} \times Y_{i, r}\left\{\left(\frac{C Y V_{i, r}}{c 0_{\_} Y_{i, r} \times C Y \_K L E V_{i, r}}\right)^{s i g m a \_M A T_{-} K L E_{i, r}}\right. \\
& \times\left(\frac{C Y \_K L E V_{i, r}}{C Y_{-} E N G V_{i, r}}\right)^{s i g m a_{-} K L E_{i, r}} \times\left(\frac{C Y \_E N G V_{i, r}}{C Y \_E L E V_{i, r}}\right)^{s i g m a \_E N G_{i, r}} \\
& \left.\times\left(\frac{C Y \_E L E V_{i, r} \times p i 0_{j, i, r}}{\left(1+t i_{j, i, r}\right) \times P A_{j, r}}\right)^{s i g m a \_E N E_{i, r}}\right\}
\end{aligned}
$$

Intermediate demand function $\mathrm{C}$ (for $\mathrm{j}=$ non-energy materials)

$$
\begin{aligned}
D E M Y_{-} Y V_{j, i, r}= & i d 0_{j, i, r} \times Y_{i, r}\left\{\left(\frac{C Y V_{i, r}}{c 0_{-} Y_{i, r} \times C Y \_M A T V_{i, r}}\right)^{s i g m a \_M A T_{-} K L E_{i, r}}\right. \\
& \left.\times\left(\frac{C Y \_M A T V_{i, r} \times p i 0_{j, i, r}}{\left(1+t i_{j, i, r}\right) \times P A_{j, r}}\right)^{s i g m a \_M A T_{i, r}}\right\}
\end{aligned}
$$

Labour demand function

$$
\begin{aligned}
D E M Y \_L V_{i, r}= & l d 0_{i, r} \times Y_{i, r}\left[\frac{C Y V_{i, r}}{c 0 \_Y_{i, r} \times C Y \_K L E V_{i, r}}\right]^{\text {sigma_MAT_KLE } E_{i, r}} \\
& \times\left[\frac{C Y \_K L E V_{i, r}}{C Y \_K L V_{i, r}}\right]^{\text {sigma_KLE } E_{i, r}}
\end{aligned}
$$

Capital demand function

$$
\begin{aligned}
D E M Y \_K V_{i, r}= & k d 0_{i, r} \times Y_{i, r}\left[\frac{C Y V_{i, r}}{c 0_{-} Y_{i, r} \times C Y \_K L E V_{i, r}}\right]^{s i g m a \_M A T_{-} K L E_{i, r}} \\
& \times\left[\frac{C Y_{-} K L E V_{i, r}}{C Y_{-} K L V_{i, r}}\right]^{s i g m a \_K L E_{i, r}} \times\left[\frac{C Y \_K L V_{i, r} \times p k 0_{i, r}}{\left(1+t k_{i, r}\right) \times P K_{r}}\right]^{s i g m a \_K L_{i, r}}
\end{aligned}
$$

\section{Market Clearing}

Market clearing output

$$
\begin{aligned}
y 0_{i, r} \times Y_{i, r}= & d 0_{i, r} \times A_{i, r} \times\left(\frac{C A V_{i, r}}{P Y_{i, r}}\right)^{s i g m a \_A_{i, r}} \\
& +\sum_{s} D E M M_{-} M V_{i, r, s}+m a e 0_{i, r} \times Y T_{i} \times \frac{\prod_{m_{-} r}\left(P Y_{i, m_{-} r}^{\text {theta } T_{i, m_{-} r}}\right)}{P Y_{i, r}}
\end{aligned}
$$


Market clearing Armington

$$
\begin{aligned}
a 0_{i, r} \times A_{i, r}= & \sum_{j} D E M Y_{-} Y V_{i, j, r}+D E M C V_{i, r}+c h_{i, r}+g d 0_{i, r} \times G E X P_{r} \\
& +i n v d 0_{i, r} \times I N V_{r}
\end{aligned}
$$

Market clearing imports

$$
m 0_{i, r} \times M_{i, r}=m 0_{i, r} \times A_{i, r} \times\left(\frac{C A V_{i, r}}{P M_{i, r}}\right)^{\text {sigma } A_{i, r}}
$$

Market clearing transport services

$$
m a 0_{i} \times Y T_{i}=\sum_{j, r, s} D E M M_{-} T V_{i, j, s, r}
$$

Market clearing capital

$$
k s 0_{r}=\sum_{i} D E M Y \_K V_{i, r}
$$

Market clearing labour

$$
l_{s} 0_{r}=\sum_{i} D E M Y \_L V_{i, r}
$$

Market clearing government consumption

$$
g 0_{i, r} \times G E X P_{r} \times P G_{r}=I N C_{-} G_{r}
$$

Market clearing private consumption

$$
c 0_{r} \times C_{r} \times P C_{r}=I N C_{-} R A_{r}
$$

Market clearing investment

$$
i n v 0_{r} \times I N V_{r}=i n v 0_{r}
$$

\section{Income Definitions}

Income of the representative agent ${ }^{15}$

$$
\begin{aligned}
I N C_{-} R A_{r}= & k s 0_{r} \times P K_{r}+l s 0_{r} \times P L_{r}-\sum_{i}\left(\left(1+t c_{i, r}\right) \times P A_{i, r} \times c h_{i, r}\right) \\
& -i n v 0_{r} \times P I N V_{r}-h \operatorname{tax} 0_{r} \times P C_{r}
\end{aligned}
$$

15 This closure assumes constant transfer payments from government to household. An alternative closure exists that can be used for revenue recycling. 
Government income ${ }^{16}$ (output tax + factor tax + intermediate input tax + final consumption tax + export tax + import tax + transfer to hhlds)

$$
\begin{aligned}
I N C_{-} G_{r}= & \sum_{i}\left(t o_{i, r} \times P Y_{i, r} \times y 0_{i, r} \times Y_{i, r}\right) \\
& +\sum_{i}\left(t k_{i, r} \times P K_{i, r} \times D E M Y \_K V_{i, r}+t l_{i, r} \times P L_{r} \times D E M Y_{-} L V_{i, r}\right) \\
& +\sum_{i, j}\left(t i_{i, j, r} \times P A_{i, r} \times D E M Y \_Y V_{i, j, r}\right) \\
& +\sum_{i}\left(t c_{i, r} \times P A_{i, r} \times\left(D E M C V_{i, r}+c h_{i, r}\right)+t g_{i, r} \times P A_{i, r} \times g 0_{i, r}\right. \\
& \left.\times G E X P_{r}+t i n v_{i, r} \times P A_{i, r} \times i n v d 0_{i, r} \times I N V_{r}\right) \\
& +\sum_{i, s}\left(t m_{i, s, r} \times\left(\left(1+t e_{i, s, r}\right) \times P Y_{i, s} \times D E M M_{-} M V_{i, s, r}\right.\right. \\
& \left.\left.+\sum_{j} P T_{j} \times D E M M_{-} T V_{j, i, s, r}\right)\right) \\
& +h t a x 0_{r} \times P C_{r}+v b_{r} \times \sum_{r \text { num }} P C_{r n u m}
\end{aligned}
$$

\section{Constraints}

Constant government budget constraint (only active if using the revenue recycling closure)

$$
G E X P_{r}=1
$$

Conflict of interest The views expressed are purely those of the authors and may not in any circumstances be regarded as stating an official position of the European Commission.

Open Access This article is distributed under the terms of the Creative Commons Attribution License which permits any use, distribution, and reproduction in any medium, provided the original author(s) and the source are credited.

\section{References}

Aaheim A, Amundsen H, Dokken T, Ericson T, Wei T (2012) Impacts and adaptation to climate change in European economies. Glob Environ Change 22:959-968

Armington PS (1969) A theory of demand for products distinguished by place of production. Int Monet Fund staff Pap 16(1):159-176

Bentley C, Thomas R, Velicogna I (2007) Ice sheets, chapter 6A in global outlook for snow and ice. UNEP

Bosello F, Roson R, Tol RSJ (2007) Economy wide estimates of the implications of climate change: sea-level rise. Environ Resour Econ 37:549-571

Bosello F, Nicholls R, Richards J, Roson R, Tol RSJ (2012) Economic impacts of climate change in Europe: sea-level rise. Clim Change 112:63-81. doi:10.1007/s10584-011-0340-1

Breil M, Gambarelli G, Nunes P (2005) Economic valuation of on site material damages of high water on economic activities based in the city of Venice: results from a dose-response-expert-based valuation approach. FEEM Nota di lavoro 53.2005. http://ssrn.com/abstract=702965

16 This closure assumes constant transfer payments from government to household. An alternative closure exists that can be used for revenue recycling. 
Burniaux J-M, Truong TP (2002) GTAP-E: an energy-environmental version of the GTAP model. GTAP Technical Paper No. 16

Capros P, Van Regemorter D, Paroussos L, Karkatsoulis P (2013) GEM-E3 model documentation. JRC Technical Report, EUR 26034 EN

Ciscar JC, Iglesias A, Feyen L, Szabó L, Van Regemorter D, Amelung B, Nicholls R, Watkiss P, Christensen O, Dankers R, Garrote L, Goodess C, Hunt A, Moreno A, Richards J, Soria A (2011) Physical and economic consequences of climate change in Europe. Proc Natl Acad Sci 108(7):2678-2683. doi:10.1073/pnas. 1011612108

Ciscar JC, Szabó L, van Regemorter D, Soria A (2012) The integration of PESETA sectoral economic impacts into GEM-E3 Europe: methodology and results. Clim Change. doi:10.1007/s10584-011-0343-y

Ciscar JC, Feyen L, Soria A, Lavalle C, Raes F, Perry M, Nemry F, Demirel H, Rozsai M, Dosio A, Donatelli M, Srivastava A, Fumagalli D, Niemeyer S, Shrestha S, Ciaian P, Himics M, Van Doorslaer B, Barrios S, Ibáñez N, Forzieri G, Rojas R, Bianchi A, Dowling P, Camia A, Libertà G, San Miguel J, de Rigo D, Caudullo G, Barredo JI, Paci D, Pycroft J, Saveyn B, Van Regemorter D, Revesz T, Vandyck T, Vrontisi Z, Baranzelli C, Vandecasteele I, Batista e Silva F, Ibarreta D (2014) Climate impacts in Europe. The JRC PESETA II project. Scientific and Technical Research series, EUR 26586-Joint Research CentreInstitute for Prospective Technological Studies

Copenhagen Diagnosis (2009) Updating the world on the latest climate science. Allison I, Bindoff NL, Bindschadler RA, Cox PM, de Noblet N, England MH, Francis JE, Gruber N, Haywood AM, Karoly DJ, Kaser G, Le Quéré C, Lenton TM, Mann ME, McNeil BI, Pitman AJ, Rahmstorf S, Rignot E, Schellnhuber HJ, Schneider SH, Sherwood SC, Somerville RCJ, Steffen K, Steig EJ, Visbeck M, Weaver AJ. The University of New South Wales Climate Change Research Centre (CCRC), Sydney, Australia

Darwin R, Tol R (2001) Estimates of the economic effects of sea level rise. Environ Resour Econ 19:113-129

Dasgupta S, Laplante B, Meisner C, Wheeler D, Yan J (2009) The impact of sea level rise on developing countries: a comparative analysis. Clim Change 93:379-388. doi:10.1007/s10584-008-9499-5

Deke O, Hooss KG, Kasten C, Klepper G, Katrin S (2001) Economic impact of climate change: simulations with a regionalised climate-economy model. Kiel Working Paper No. 1065. Kiel Institute of World Economics, Germany

Delta Committee (2008) Working together with water: a living land build for its future. Deltacommissie, The Netherlands

DINAS-Coast Consortium (2006) DIVA: version 1.0. CD-ROM. Potsdam Institute for Climate Impact Research, Potsdam

Fankhauser S (1995) Protection versus retreat: the economic costs of sea-level rise. Environ Plan A 27(2):299319

Floodsite (2006) Guidelines for socio-economic flood damage evaluation. Co-funded by Sixth Framework programme for European Research and Technological Development. Report number T9-06-01. Coordinated by HR Wallingford, UK

Fouré J, Bénassy-Quéré A, Fontagné L (2012) The great shift: MaGE projections for the world economy at the 2050 Horizon, CEPII Working Paper 2012-03

Grinsted A, Moore J, Jevrejeva S (2010) Reconstructing sea level from paleo and projected temperatures 200 to 2100AD. Clim Dyn 34(4):461-472. doi:10.1007/s00382-008-0507-2

Hallegatte S (2012) A framework to investigate the economic growth impact of sea level rise. Environ Res Lett 7:015604. doi:10.1088/1748-9326/7/1/015604

Hansen J (2007) Scientific reticence and sea level rise. Environ Res Lett 2:024002. doi:10.1088/1748-9326/ $2 / 2 / 024002$

Heberger M, Cooley H, Herrera P, Gleick P, Moore E (2011) Potential impacts of increased coastal flooding in California due to sea-level rise. Clim Change 109(Suppl 1):S229-S249

Hertel T (1997) Global trade analysis: modeling and applications. Cambridge University Press, Cambridge. https://www.gtap.agecon.purdue.edu/products/gtap_book.asp

Hof AF, Hope C, van Vuuren DP (2013) Sea-level rise damage and adaptation costs: a comparison of model costs estimates. In: Proceedings of the impacts world 2013, international conference on climate change effects, Potsdam

IPCC (2007) Summary for policymakers. In: Solomon S, Qin D, Manning M, Chen Z, Marquis M, Averyt KB, Tignor M, Miller HL (eds) Climate change 2007: the physical science basis. Contribution of Working Group I to the fourth assessment report of the intergovernmental panel on climate change. Cambridge University Press, Cambridge, UK and New York, NY, USA

Kopp R, Simons F, Mitrovica J, Maloof A, Oppenheimer M (2009) Probabilistic assessment of sea level during the last interglacial stage. Nature 462:863-867. doi:10.1038/nature08686

Kriegler E, Hall J, Helda H, Dawson R, Schellnhuber HJ (2009) Imprecise probability assessment of tipping points in the climate system. Proc Natl Acad Sci 106(13):5041-5046 
Lenton T, Held H, Kriegler E, Hall J, Lucht W, Rahmstorf S, Schellnhuber HJ (2008) Tipping elements in the Earth's climate system. Proc Natl Acad Sci 105(6):1786-1793. http://www.pnas.org/content/105/6/ 1786.full.pdf

Losada IJ, Reguero BG, Méndez FJ, Castanedo S, Abascal AJ, Mínguez R (2013) Long-term changes in sea-level components in Latin America and the Caribbean. Glob Planet Change 104:34-50. doi:10.1016/ j.gloplacha.2013.02.006; ISSN 0921-8181

Lowe J, Gregory J (2010) A sea of uncertainty. Nat Rep Clim Change 4:42-43

McFadden L, Nicholls RJ, Vafeidis AT, Tol RSJ (2007) A methodology for modelling coastal space for global assessments. J Coast Res 23(4):911-920

Meehl G, Stocker T, Collins W, Friedlingstein P, Gaye A, Gregory J, Kitoh A, Knutti R, Murphy J, Noda A, Raper S, Watterson I, Weaver A, Zhao Z-C (2007) Global climate projections. Climate change 2007: the physical science basis. Contribution of Working Group I to the fourth assessment report of the intergovernmental panel on climate change, pp 747-846. http://www.ipcc.ch/pdf/assessment-report/ar4/ wg1/ar4-wg1-chapter10.pdf

Morisugi H, Ohno E, Hoshi K, Takagi A, Takahashi Y (1995) Definition and measurement of a household's damage cost caused by an increase in storm surge frequency due to sea level rise. J Glob Environ Eng $1: 127-136$

Narayanan G, Badri AA, McDougall R (eds) (2012) Global trade, assistance, and production: the GTAP 8 data base. Center for Global Trade Analysis. Purdue University

Nicholls R, Hanson S, Herweijer C, Patmore N, Hallegatte S, Corfee-Morlot J, Chateau J, Muir-Wood R (2007) Ranking of the world's cities most exposed to coastal flooding today and in the future: executive summary, OECD Environment Working Paper No. 1 (ENV/WKP(2007) 1)

Nicholls R, Tol R, Vafeidis A (2008) Global estimates of the impact of a collapse of the West Antarctic ice sheet: an application of FUND. Clim Change 91:171-191. doi:10.1007/s10584-008-9424-y

Paltsev S, Reilly JM, Jacoby HD, Eckaus RS, McFarland J, Sarofim M, Asadoorian M, Babiker M (2005) The MIT Emission Prediction and Policy Analysis (EPPA) model: version 4. MIT Joint Program on the Science and Policy of Global Change, Report 125

Rahmstorf S (2007) A semi-empirical approach to projecting future sea-level rise. Science 315:368-370

Saizar A (1997) Assessment of a potential sea level rise on the coast of Montevideo, Uruguay. Clim Res 9:73-79

Smith J, Lazo J (2001) A summary of climate change impact assessments from the US country studies programme. Clim Change 50:1-29

Smith JB, Schneider SH, Oppenheimer M, Yohe GW, Hare W, Mastrandrea MD, Patwardhan A, Burton I, Corfee-Morlot J, Magadza CHD, Fussel HM, Pittock AB, Rahman A, Suarez A, van Ypersele JP (2009) Assessing dangerous climate change through an update of the Intergovernmental Panel on Climate Change (IPCC) 'reasons for concern'. Proc Natl Acad Sci USA 106:4133-4137 (2009)

Tol RSJ (2006) The DIVA model: socio-economic scenarios, impacts and adaptation and world heritage. In: DINAS-COAST consortium 2006. DIVA 1.5.5. Potsdam: Potsdam Institute for Climate Impact Research, CD-ROM. http://www.pik-potsdam.de/diva

Vafeidis AT, Nicholls RJ, McFadden L, Tol RSJ, Spencer T, Grashoff PS, Boot G, Klein RJT (2008) A new global coastal database for impact and vulnerability analysis to sea-level rise. J Coast Res 24(4):917-924

Van Koningsveld M, Mulder JPM, Stive MJF, van der Valk L, van der Weck AW (2008) Living with sea-level rise and climate change: a case study of the Netherlands. J Coast Res 24(2):367-379

Velicogna I (2009) Increasing rates of ice mass loss from the Greenland and Antarctic ice sheets revealed by GRACE. Geophys Res Lett 36:L19503. doi:10.1029/2009GL040222

Weaver A, Saenko O, Clark P, Mitrovica J (2003) Meltwater pulse 1A from Antarctica as a trigger of the Bølling-Allerød warm interval. Science 299:1709. doi:10.1126/science.1081002 